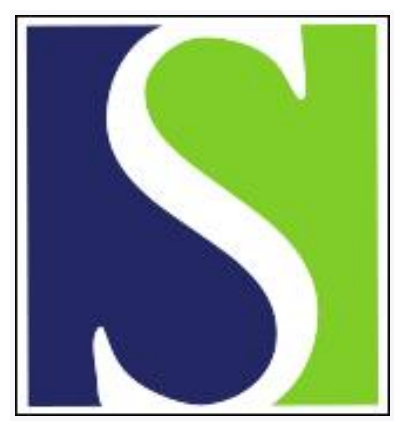

Scand J Work Environ Health 1978;4(1):29-38

https://doi.org/10.5271/sjweh.2766

Issue date: 1978

Restriction and pain during forward bending in concrete reinforcement workers.

by Wickström G, Nummi J, Nurminen M

Key terms: concrete reinforcement work; concrete reinforcement worker; concrete work; forward bending; lumbar flexion; pain; restriction

This article in PubMed: www.ncbi.nlm.nih.gov/pubmed/149366

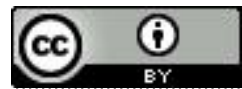


Scand. j. work environ. \& health 4 (1978): suppl. 1, 29-38

\title{
Restriction and pain during forward bending in concrete reinforcement workers
}

\author{
by GUSTAV WICKSTRÖM, M.D.,1 JUHANI NUMMI, M.D.,² and \\ MARKKU NURMINEN, L.Sc. ${ }^{2}$
}

\begin{abstract}
WICKSTRÖM, G., NUMMI, J. and NURMINEN, M. Restriction and pain in concrete reinforcement workers during forward bending. Scand. $j$. work environ. \& health 4 (1978): suppl. 1, 29-38. Two hundred and ninety-five male Finnish concrete reinforcement workers, aged 19-64 years and engaged in heavy physical work including prolonged stooping, were clinically examined in a cross-sectional study. Restriction of lumbar flexion was found in $38 \%$ of the men, and pain during forward bending in $19 \%$. Restriction of lumbar flexion was strongly related to age, while pain during forward bending showed a weaker association. A history of sciatica was more common in the men with restriction during forward bending $\left(\chi^{2}=6.0, \mathrm{p}<0.05\right)$ and in the men with pain during forward bending $\left(\chi^{2}=17.2\right.$, $\mathrm{p}<0.001$ ) than in the men without. Restricted lumbar flexion was related to diminished back muscle performance capacity $\left(\chi^{2}=18.7, \mathrm{p}<0.001\right)$ and straight abdominal muscle performance capacity $\left(\chi^{2}=28.0, p<0.001\right)$. Pain during forward bending was also related to diminished back muscle $\left(\chi^{2}=25.3, p<0.001\right)$ and straight abdominal muscle $\left(\chi^{2}=21.2, p<0.001\right)$ performance capacity. The prevalence of radiologically detectable lumbar disc degeneration was associated with restricted lumbar flexion $\left(\chi^{2}=20.2, \mathrm{p}<0.001\right)$. Comparison of the occurrence of restricted lumbar flexion and pain during forward bending to length of reinforcement work experience showed no relation after adjustment for age. When reinforcement workers were compared to computer technicians, restricted lumbar flexion was equally common in both groups, while the occurrence of pain during forward bending was more common among reinforcement workers $\left(\chi^{2}=8.6, \mathrm{p}<0.01\right)$.
\end{abstract}

Key words: concrete reinforcement worker lumbar flexion, pain, restriction.

A full range of active spinal movement implies normal physical properties of the intervertebral discs, normal activity in the trunk muscles, and undisturbed function of the facet joints. The most common causes of restricted movement in the lumbar spine are pain and disc degeneration. Ankylosing spondylitis, impairing the function of the facet joints, and restriction

1 Turku Regional Institute of Occupational Health, Turku, Finland.

2 Institute of Occcupational Health, Helsinki, Finland. of the lumbar movement from pronounced muscle contraction are both rare conditions in active construction workers.

To evaluate the possible effect of concrete reinforcement work on the back of the workers, we have carried out an epidemiologic, cross-sectional study of reinforcement workers. In this article we have described the age dependence of restriction and pain during forward bending, analyzed the data for a possible effect of reinforcement work on lumbar movement, and compared clinically recorded restriction and pain during forward bend- 
ing with anamnestic, clinical and radiological findings of lumbar disc degeneration.

\section{MATERIAL AND METHODS}

\section{Material}

Two hundred and ninety-five male Finnish concrete reinforcement workers, aged 19 to 64 years, were examined. The age distribution and the occupational history of the group studied have been presented in an article by Wickström et al. (16). The exceptionally high exposure to stooped work postures in the reinforcement trade has been established in an ergonomic study (15).

The program for the clinical orthopedic investigation used in this study was developed at the Institute of Occupational Health in Helsinki for use in epidemiologic research. The men were interviewed and examined by a physiotherapist specially trained for the task.

Restriction of forward bending was determined through the measurement of the distance between the spinous processes of the first sacral and the twelfth thoracic vertebra of a subject in the upright and stooped position (2). The reinforcement worker was asked to bend smoothly forward as much as he could and report possible pain. The degree of movement was recorded as the increase in distance between the spinal processes: $7 \mathrm{~cm}$ or more $(\geq 65 \mathrm{~mm}$ ) was considered normal, $5-6 \mathrm{~cm}(45-64 \mathrm{~mm})$ slightly reduced, $3-4 \mathrm{~cm}(25-44 \mathrm{~mm})$ moderately reduced, and $2 \mathrm{~cm}$ or less $(\leq 24 \mathrm{~mm})$ strongly reduced. Pain during the forward bending movement was explicitly asked for at the examination and recorded when reported.

The method for gathering the anamnestic data has been presented in an article by Wickström et al. (16); due to an expansion of the interview on symptoms during the course of the study, specific questions on present back symptoms were presented to only 223 workers. The methods for measuring trunk muscle performance capacity have been described by Nummi et al. (13) and the radiological methods by Wiikeri et al. (17).

\section{Statistical methods}

For simplicity it was assumed that all the concrete reinforcement workers falling into the same age group could be treated as having identical ages; these ages were then considered as equally spaced for the ten age groups. The age-dependent proportions of observed restriction and/or pain during forward bending were smoothed by calculation of 15-year moving averages. The smoothed prevalence estimates and their logistic type of metameters were presented graphically according to the presentation of Mantel and Brown (8). With the use of a weighted regression technique, linear models were fitted to these data. In the first fit in the form of $P=a+b(A)$, where $P$ is the population prevalence rate, $\mathrm{A}$ denotes age (group), and $a$ and $b$ the estimated parameters of the model, the possible response combinations were treated as distinct categories. The number of subjects in the age groups were used to weight the observed proportions (fig. 1). A chi-square statistic for testing the significance of the differences among the age groups could be proportioned into two additive components, i.e., one for testing whether the association between "P" and age was linear and another to test the significance of the slope of the regression line; symbolically

$$
\chi^{2} \text { homogeneity }=\chi^{2} \text { linearity }+\chi^{2} \text { slope }
$$

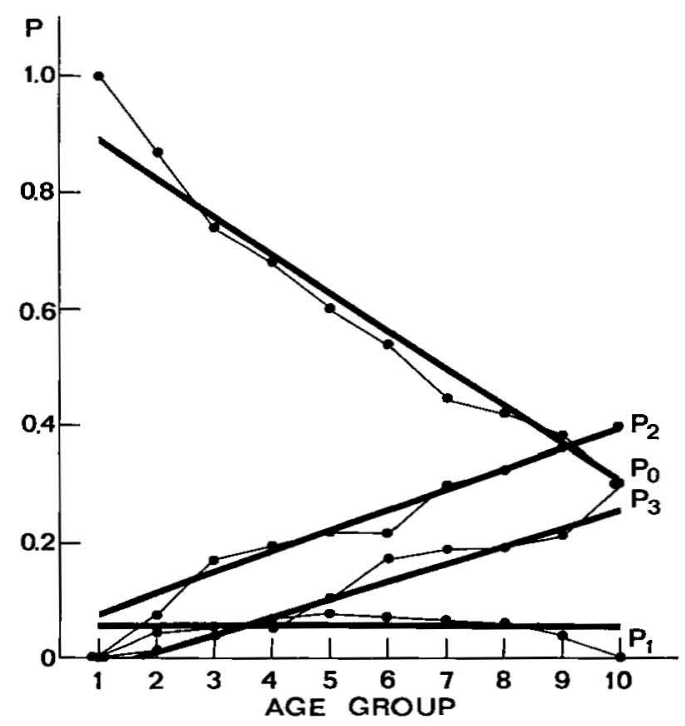

Fig. 1. Proportion of subjects with restriction and/or pain during forward bending as a function of age. $\left(\mathrm{P}_{0}=\right.$ proportion of subjects with neither finding; $P_{1}=$ proportion with pain alone; $\mathrm{P}_{2}=$ proportion with restriction alone; $\mathrm{P}_{3}=$ proportion with both restriction and pain; smoothed observed data $=-(-)$; graduated data fitted under linear model $=\longrightarrow$ ) 
Table 1. Number of subjects with restriction and/or pain during forward bending.

\begin{tabular}{|c|c|c|c|c|c|c|}
\hline \multirow{2}{*}{\multicolumn{2}{|c|}{$\begin{array}{l}\text { Forward bending restricted } \\
\text { Forward bending painful }\end{array}$}} & \multicolumn{2}{|c|}{ No } & \multicolumn{2}{|c|}{ Yes } & \multirow[b]{2}{*}{ Total } \\
\hline & & No & Yes & No & Yes & \\
\hline \multicolumn{7}{|c|}{$\begin{array}{lc}\text { Age group } & \begin{array}{l}\text { Number of } \\
\text { age group }\end{array} \\
\text { (years) } & \text { (A) }\end{array}$} \\
\hline $15-19$ & 1 & 1 & - & - & - & 1 \\
\hline $20-24$ & 2 & 12 & - & 1 & 1 & 14 \\
\hline $25-29$ & 3 & 24 & 1 & 5 & 2 & 32 \\
\hline $30-34$ & 4 & 27 & 4 & 13 & 1 & 45 \\
\hline $35-39$ & 5 & 35 & 4 & 7 & 5 & 51 \\
\hline $40-44$ & 6 & 30 & 4 & 13 & 11 & 58 \\
\hline $45-49$ & 7 & 15 & 2 & 10 & 8 & 35 \\
\hline $50-54$ & 8 & 11 & 2 & 11 & 4 & 28 \\
\hline $55-59$ & 9 & 9 & 1 & 6 & 4 & 20 \\
\hline $60-64$ & 10 & 3 & - & 4 & 3 & 10 \\
\hline \multicolumn{2}{|l|}{ Total } & 167 & 18 & 70 & 39 & 294 \\
\hline
\end{tabular}

with a respective partition of the degrees of freedom $\mathrm{m}-1=(\mathrm{m}-2)+1$. The logittransformed prevalences (figs. 2 and 3 ) received a set of weights in the estimation of the parameters of the linear model, by which both the number of observations and the accuracy of the prevalence estimates were taken into account.

For the study of the effect of concrete reinforcement work on restriction and pain in forward bending, an adjustment was made via application of Mantel's (7) extension of the Mantel-Haenszel procedure for analyzing multiple $2 \times \mathrm{k}$ contingency tables and establishing associations. We computed chi-squares singly for 5-year age intervals and a summary chisquare for combined age intervals, both with one degree of freedom.

To relate the frequency of clinically recorded restriction and pain in forward bending to anamnestic and other clinical findings as well as to radiological ones, we arranged the observed frequencies into two-way dichotomous classification tables suitable for significance testing; a chi-square test without Yates' correction was computed along with a tetrachoric correlation coefficient $\mathrm{r}_{\mathrm{t}}$; symbolically

$$
\mathrm{r}_{\mathrm{t}}=\sqrt{\chi^{2 / \mathrm{N}}}
$$

where $\mathrm{N}$ is the total number of subjects studied.

\section{RESULTS}

When the subjects bent forward, the distance between the spinous processes of Th XII and S I grew $7 \mathrm{~cm}$ or more in 62 $\%$ of the men examined. In $29 \%$ the difference was 5 to $6 \mathrm{~cm}$, in $7 \% 3$ to 4 $\mathrm{cm}$, and in $1 \%$ it was $2 \mathrm{~cm}$ or less. Forward bending was reported to be painful by $20 \%$ of the men.

The dichotomous data on clinically restricted forward bending (i.e., $\geq 65$ or $<65 \mathrm{~mm}$ ), combined with the data for pain during forward bending, appear in table 1, which shows for each of the ten 5 -year age groups the number of individuals falling into four combinations; individuals having neither finding being designated by category $\mathrm{i}=0$, pain alone $\mathrm{i}=$ 1 , restriction alone $\mathrm{i}=2$, both findings together $\mathrm{i}=3$.

In fig. 1 the proportion of men falling into each category is shown as a function of age. The proportion of men without pain or restriction during forward bending $(i=0)$ falls sharply with age; the proportion of those with restriction alone $(i=2)$ increases steadily with age; the proportion of men with pain and restriction $(i=3)$ shows an equally rapid rise with age but on a lower prevalence level; the proportion of men with painful forward bending alone $(i=1)$ remains stable on a low level.

Table 2 a gives the frequencies obtained in the estimation of the parameters in fig. 1 when they are fitted for the weighted linear regression. Statistical determinations were made of the adequacy of each fitted model with the chi-square tests introduced in the methods section. The usual chi-square for testing the homogeneity of proportions yielded a significant value only for category 0 . The chi-square for testing the linearity gave nonsignificant 
values for all categories, while the chi-square values for testing the slope were significant for categories 0,2 and 3 (table $2 \mathrm{~b}$ ).

Fig. 2 shows, on a logarithmic scale, the proportion of workers falling into each of the categories 1, 2 and 3 relative to the cases falling into category 0 in each age group for both smoothed data, and the results fitted under the linear model. On visual inspection the relationships for categories 2 and 3 appear to be substantially linear.

A third graphic presentation is given in fig. 3 , which shows the marginal log odds for each finding separately. The fit to marginal logits for restriction is reasonably good. For pain, the marginal logits increase linearly with age up to 40 years, whereafter they level off.

Because the age of the worker and the length of his reinforcement work experience were interrelated (correlation coefficient $r=0.76$ ), the latter variable was transformed into a relative quantity by dividing it with the variable "age 15." This transformed variable was technically independent of age (observed $r=0.11$ ). The examination of a possible association of orthopedic findings with the occupational factors could then be performed with the effect of age held constant. However, the calculation of partial correlation coefficients, after elimination of the variation due to age, produced nearly zero coefficients between work experience and the findings of restriction or pain during forward bending. Similarly, linear regression analysis was incapable of distinguishing a separate effect of work in addition to that explained by

Table 2 a. Subjects with restriction and/or pain during forward bending; fitted cell frequencies and parameters under linear model for proportions.

\begin{tabular}{|c|c|c|c|c|}
\hline \multirow{2}{*}{$\begin{array}{l}\text { Forward bending restricted } \\
\text { Forward bending painful }\end{array}$} & \multicolumn{2}{|c|}{ No } & \multicolumn{2}{|c|}{ Yes } \\
\hline & No & Yes & No & Yes \\
\hline \multicolumn{5}{|l|}{$\begin{array}{l}\text { Midpoint of } \\
\text { age interval } \\
\text { (years) }\end{array}$} \\
\hline $\begin{array}{l}17.5 \\
22.5 \\
27.5 \\
32.5 \\
37.5 \\
42.5 \\
47.5 \\
52.5 \\
57.5 \\
62.5\end{array}$ & $\begin{array}{r}0.9 \\
11.4 \\
23.9 \\
30.6 \\
31.2 \\
31.7 \\
16.8 \\
11.6 \\
6.9 \\
2.8\end{array}$ & $\begin{array}{l}0.1 \\
0.8 \\
1.9 \\
2.6 \\
3.0 \\
3.4 \\
2.0 \\
1.6 \\
1.2 \\
0.6\end{array}$ & $\begin{array}{r}0.1 \\
1.5 \\
4.5 \\
8.1 \\
11.0 \\
14.5 \\
10.0 \\
9.0 \\
7.1 \\
3.9\end{array}$ & $\begin{array}{l}0.0 \\
0.3 \\
1.6 \\
3.7 \\
5.8 \\
8.4 \\
6.2 \\
5.8 \\
4.8 \\
2.7\end{array}$ \\
\hline $\begin{array}{c}\text { Parameter } \\
\mathrm{a}_{\mathrm{i}} \\
\mathrm{b}_{\mathrm{i}}\end{array}$ & $\begin{array}{r}1.111 \\
-0.013\end{array}$ & $\begin{array}{l}0.059 \\
-0.00001\end{array}$ & $\begin{array}{r}-0.047 \\
0.007\end{array}$ & $\begin{array}{r}-0.121 \\
0.006\end{array}$ \\
\hline
\end{tabular}

Table $2 \mathrm{~b}$. Chi-square significance tests and associated significance levels for proportions graduated under linear model. Key: Each cell consists of chi-square, degrees of freedom and p-value. (NS = not significant)

\begin{tabular}{|c|c|c|c|c|}
\hline \multirow{2}{*}{ Tests for: } & \multicolumn{4}{|c|}{ Orthopedic finding category } \\
\hline & $i=0$ & $\mathrm{i}=1$ & $\mathrm{i}=\mathbf{2}$ & $i=3$ \\
\hline Homogeneity & $\begin{array}{c}22.5 \\
\mathbf{9} \\
<0.01\end{array}$ & $\begin{array}{l}2.18 \\
9 \\
\text { NS }\end{array}$ & $\begin{array}{l}9.04 \\
9 \\
\text { NS }\end{array}$ & $\begin{array}{c}11.3 \\
9 \\
\text { NS }\end{array}$ \\
\hline Linearity & $\begin{array}{l}0.57 \\
8 \\
\text { NS }\end{array}$ & $\begin{array}{l}2.18 \\
8 \\
\text { NS }\end{array}$ & $\begin{array}{l}0.74 \\
8 \\
\text { NS }\end{array}$ & $\begin{array}{l}0.95 \\
8 \\
\text { NS }\end{array}$ \\
\hline Slope & $\begin{array}{c}22.0 \\
1 \\
<0.001\end{array}$ & $\begin{array}{l}0.00005 \\
1 \\
\mathrm{NS}\end{array}$ & $\begin{aligned} & 8.30 \\
1 & \\
< & 0.01\end{aligned}$ & $\begin{array}{c}10.3 \\
1 \\
<0.01\end{array}$ \\
\hline
\end{tabular}


AGE GROUP

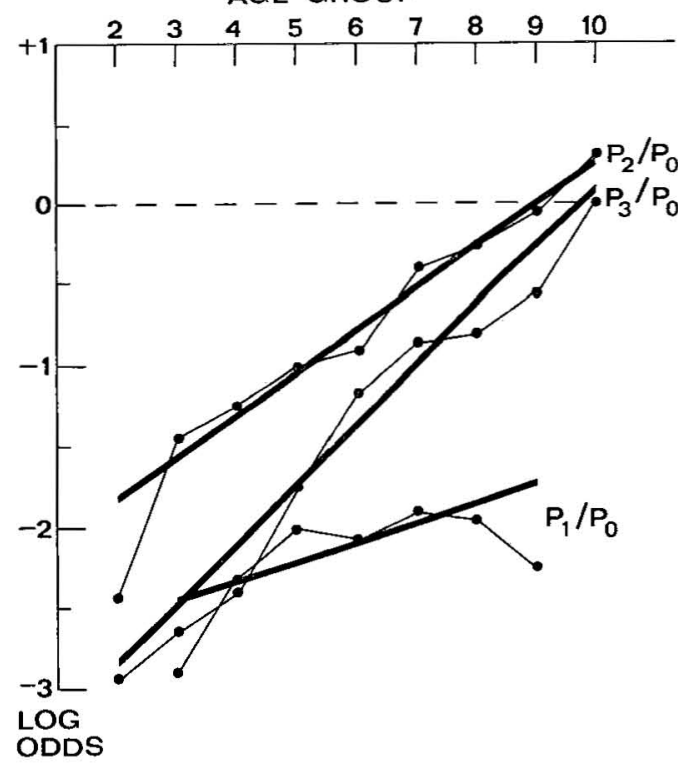

Fig. 2. Logits for proportion of subjects in each finding category as a function of age. (Smoothed observed data $=0-1$; graduated data fitted under linear model $=\longrightarrow$ )

age alone. The extension of the MantelHaenszel procedure (7) for testing the significance of association in multiple $2 \times$ $\mathrm{k}$ contingency tables was applied for the analysis of the association between work experience and the prevalence of restriction and pain during forward bending. The chi-square values computed separately for 5-year age intervals and for the combined age interval were both found to be nonsignificant.

An age-adjusted comparison of the findings for reinforcement workers to corresponding data for computer technicians, obtained in another cross-sectional study employing identical methods of investigation (12), showed that restricted lumbar flexion was equally common in both groups, while pain during forward bending was more common among reinforcement workers $\left(\chi^{2}=8.6, \mathrm{p}<0.01\right)$ (fig. 4).

To relate the findings of restriction and pain during forward bending to other data, we divided the concrete reinforcement workers into those with restriction of the forward bending movement and those without, as well as into those with

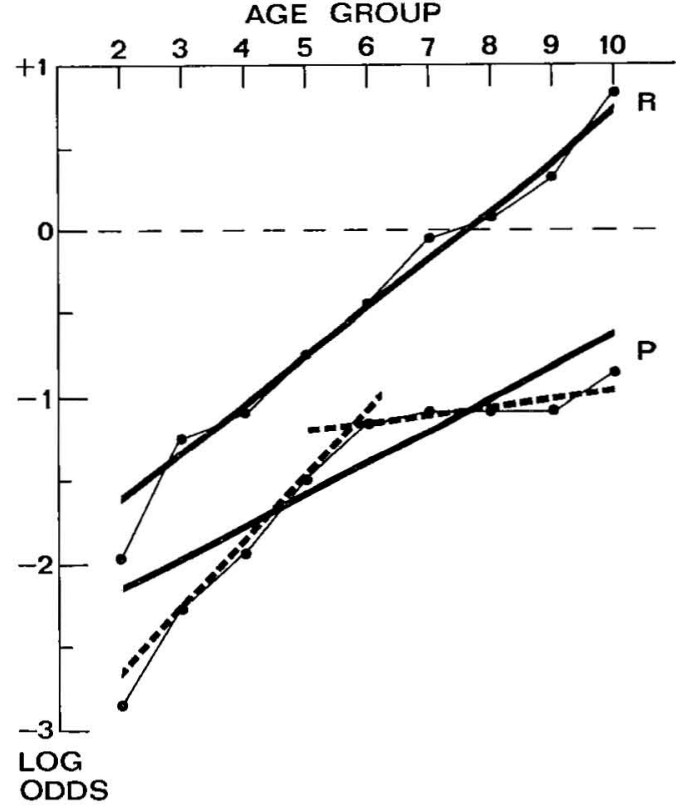

Fig. 3. Marginal logits for restriction (R) and pain (P) during forward bending as a function of age. $\left[R=\log \left[\left(p_{2}+p_{3}\right) /\left(p_{0}+p_{1}\right)\right] ; P=\log \right.$ $\left[\left(p_{1}+p_{3}\right) /\left(p_{0}+p_{2}\right)\right] ;$ smoothed observed data $=$ - ; graduated data fitted under linear model $=-$ and --- ].

pain in this movement and those without. Tables 3, 4, 5 and 6 show the prevalence of certain anamnestic, clinical orthopedic, and radiological findings in the workers with and without restriction or pain during forward bending.

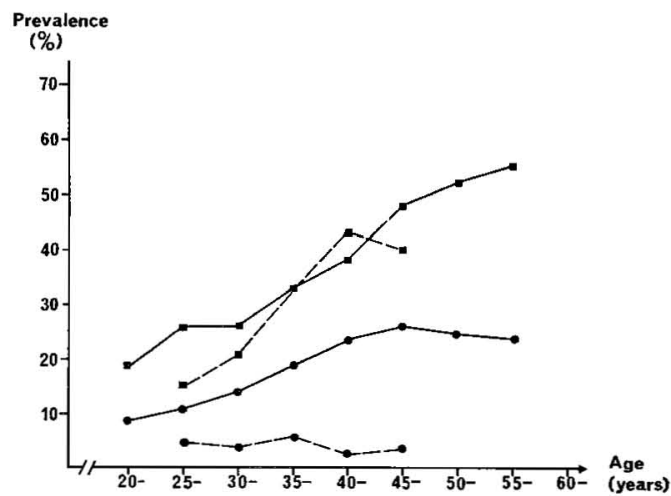

Fig. 4. Smoothed prevalence estimates for reported previous sciatica in reinforcement workers (- a) and computer technicians (1--- a) and for reported previous lumbago in reinforcement workers (-) and computer technicians $(---\bullet)$ by age. 
Table 3. Prevalence $(\%)$ of reported previous back syndromes in concrete reinforcement workers with and without restriction or pain during forward bending.

\begin{tabular}{lccccc}
\hline & \multicolumn{2}{c}{ Restriction } & & \multicolumn{2}{c}{ Pain } \\
\cline { 2 - 3 } \cline { 5 - 6 } $\begin{array}{l}\text { Previous low-back } \\
\text { pain syndrome }\end{array}$ & $\begin{array}{c}\text { Forward } \\
\text { bending } \\
\text { restricted } \\
(\mathrm{N}=109)\end{array}$ & $\begin{array}{c}\text { Forward } \\
\text { bending not } \\
\text { restricted } \\
(\mathrm{N}=185)\end{array}$ & & $\begin{array}{c}\text { Forward } \\
\text { bending } \\
\text { painful } \\
(\mathrm{N}=57)\end{array}$ & $\begin{array}{c}\text { Forward } \\
\text { bending not } \\
\text { painful } \\
(\mathrm{N}=236)\end{array}$ \\
\hline $\begin{array}{l}\text { Lumbago } \\
\text { Sciatica }\end{array}$ & $\mathbf{3 5}$ & & 31 & 39 & 36 \\
\hline
\end{tabular}

Table 4. Incidence $(\%)$ of present low-back symptoms in reinforcement workers with and without restriction or pain during forward bending.

\begin{tabular}{|c|c|c|c|c|}
\hline \multirow[b]{2}{*}{$\begin{array}{l}\text { Present } \\
\text { symptoms }\end{array}$} & \multicolumn{2}{|c|}{ Restriction } & \multicolumn{2}{|c|}{ Pain } \\
\hline & $\begin{array}{l}\text { Forward } \\
\text { bending } \\
\text { restricted } \\
(\mathrm{N}=73-74)\end{array}$ & $\begin{array}{c}\text { Forward } \\
\text { bending not } \\
\text { restricted } \\
(\mathrm{N}=148-149)\end{array}$ & $\begin{array}{c}\text { Forward } \\
\text { bending } \\
\text { painful } \\
(\mathrm{N}=42-43)\end{array}$ & $\begin{array}{c}\text { Forward } \\
\text { bending not } \\
\text { painful } \\
(\mathrm{N}=179-180)\end{array}$ \\
\hline Fatigue & 61 & 40 & 60 & 43 \\
\hline Stiffness & 47 & 38 & 51 & 38 \\
\hline Ache & 59 & 46 & 84 & 43 \\
\hline Sharp pain & 14 & 13 & 21 & 12 \\
\hline Back symptoms & & & & \\
\hline bending down & 51 & 36 & 72 & 34 \\
\hline $\begin{array}{l}\text { Back symptoms in } \\
\text { the stooped postur } \\
\text { Back symptoms }\end{array}$ & $\begin{array}{l}\text { in } \\
\text { ire }\end{array}$ & 70 & 90 & 68 \\
\hline straightening up & 65 & 61 & 72 & 60 \\
\hline
\end{tabular}

Table 5. Prevalence $(\%)$ of diminished trunk muscle performance capacity in concrete reinforcement workers with and without restriction or pain during forward bending.

\begin{tabular}{lcccccc}
\hline & \multicolumn{2}{c}{ Restriction } & & \multicolumn{2}{c}{ Pain } \\
\cline { 2 - 3 } \cline { 5 - 6 } $\begin{array}{l}\text { Diminished } \\
\text { trunk muscle } \\
\text { performance } \\
\text { capacity }\end{array}$ & $\begin{array}{c}\text { Forward } \\
\text { bending } \\
\text { restricted } \\
(\mathrm{N}=104-109)\end{array}$ & $\begin{array}{c}\text { Forward } \\
\text { bending not } \\
\text { nestricted } \\
(\mathrm{N}=178-185)\end{array}$ & & $\begin{array}{c}\text { Forward } \\
\text { bending } \\
\text { painful } \\
(\mathrm{N}=55-56)\end{array}$ & $\begin{array}{c}\text { Forward } \\
\text { bending not } \\
\text { painful } \\
(\mathrm{N}=226-237)\end{array}$ \\
$\begin{array}{l}\text { Back muscle } \\
\begin{array}{l}\text { Straight ab- } \\
\text { dominal muscles }\end{array}\end{array}$ & 42 & 19 & & 54 & 21 \\
\hline
\end{tabular}

Table 6. Prevalences $(\%)$ of restricted forward bending by degree of radiologically detectable lumbar disc degeneration.

\begin{tabular}{|c|c|c|c|c|}
\hline \multirow[b]{2}{*}{$\begin{array}{l}\text { Lumbar disc } \\
\text { degeneration }\end{array}$} & \multicolumn{4}{|c|}{ Restriction of forward bending } \\
\hline & $\begin{array}{c}\text { None } \\
(\mathrm{N}=185)\end{array}$ & $\begin{array}{l}\text { Slight } \\
(\mathrm{N}=87)\end{array}$ & $\begin{array}{c}\text { Moderate } \\
\text { or severe } \\
(\mathrm{N}=23)\end{array}$ & $\begin{array}{c}\text { Total } \\
(\mathrm{N}=295)\end{array}$ \\
\hline None & 66 & 41 & 30 & 56 \\
\hline Slight & 12 & 10 & 17 & 12 \\
\hline Moderate & 17 & 33 & 26 & 23 \\
\hline Severe & 5 & 15 & 26 & 9 \\
\hline Total & 100 & 100 & 100 & 100 \\
\hline
\end{tabular}


A history of lumbago was not related to restriction or pain during forward bending, but a history of sciatica was reported significantly more commonly among the men with restriction $\left(\chi^{2}=6.0\right.$, $\left.\mathrm{p}<0.05, \quad \mathrm{r}_{\mathrm{t}}=0.14\right)$ and pain $\left(\chi^{2}=17.2\right.$, $\left.\mathrm{p}<0.001, \mathrm{r}_{\mathrm{t}}=0.24\right)$ than among those without (table 3 ).

When restricted forward bending was compared with back symptoms during an ordinary workday, some relation was found to reported fatigue $\left(\chi^{2}=8.9, \mathrm{p}<0.01\right.$, $\left.r_{t}=0.17\right)$. Pain during forward bending in the clinical examination was related to the reports of fatigue $\left(\chi^{2}=4.1, \mathrm{p}<0.05\right.$, $\left.r_{\mathrm{t}}=0.12\right)$ and ache $\left(\chi^{2}=23.3, \mathrm{p}<0.001\right.$, $\mathrm{r}_{\mathrm{t}}=0.28$ ) during an ordinary workday. A considerable part of the men not experiencing pain during forward bending in the clinical examination reported back symptoms during the workday (table 4).

The incidence of back symptoms in the stooped posture during an ordinary workday was as high as $73 \%$. In a comparison of the reports of symptoms on adopting the stooped position, on being in it, and on leaving it with the results from the clinical examination, the very frequent reports of symptoms in the stooped posture and on straightening up showed no clear relation to restriction and pain during forward bending. The less common reports of symptoms as the worker bent down showed a slight relation to restriction $\left(\chi^{2}=4.7, \mathrm{p}<0.05, \mathrm{r}_{\mathrm{t}}=0.13\right)$ and a clear relation to pain $\left(\chi^{2}=20.9, \mathrm{p}<0.001, \mathrm{r}_{\mathrm{t}}=\right.$ 0.27 ) during forward bending (table 4).

The performance of the straight abdominal muscles was twice as often impaired in the men with restriction $\left(\chi^{2}=\right.$ $\left.28.0, \mathrm{p}<0.001, \mathrm{r}_{\mathrm{t}}=0.31\right)$ or pain $\left(\chi^{2}=\right.$ $21.2, \mathrm{p}<0.001, \mathrm{r}_{\mathrm{t}}=0.27$ ) during forward bending in the clinical examination as in those without. Impaired back muscle performance was also strongly related to restriction $\left(\chi^{2}=18.7, \mathrm{p}<0.001, \mathrm{r}_{\mathrm{t}}=0.25\right)$ and pain $\left(\chi^{2}=25.3, \mathrm{p}<0.001, \mathrm{r}_{\mathrm{t}}=0.29\right)$ during forward bending (table 5).

Radiologically detectable lumbar disc degeneration was found in one-third of the men without restriction of forward bending and in two-thirds of the men with restricted movement. The proportions were nearly the same for pain during forward bending.

As the capacity to bend forward diminished, the prevalence of radiologically de- tectable lumbar disc degeneration increased $\left(\chi^{2}=20.2, p<0.001, r_{t}=0.26\right)$. In the men with an increase in distance between the spinous processes of $7 \mathrm{~cm}$ or more, lumbar degeneration was found in $34 \%$. If the distance increased only 5 to $6 \mathrm{~cm}$, degeneration was found in $59 \%$, and, if it stayed at $4 \mathrm{~cm}$ or less, lumbar degeneration was present in $72 \%$. Both moderate $\left(\chi^{2}=8.3, \mathrm{p}<0.01, \mathrm{r}_{\mathrm{t}}=0.17\right)$ and severe $\left(\chi^{2}=12.4, \mathrm{p}<0.001, \mathrm{r}_{\mathrm{t}}=0.21\right)$ disc degeneration were related to the degree of restriction during forward bending (table 6).

\section{DISCUSSION}

The movement of bending forward depends on the structure of the hip, sacro-iliac, lumbosacral, and lumbar intervertebral joints, as well as on the surrounding ligaments and muscles.

The forward bending movement in the spine primarily takes place in the cervical and lumbar regions. In the lumbar spine most of the movement occurs between the lowest vertebrae (1). This phenomenon is due to the direction of the intervertebral joint surfaces in this part of the spine and to the thickness of the intervertebral discs in the low back. The plasticity of the lumbar intervertebral discs permits sagittal compression of one edge of the disc with compensatory expansion of the other (3). The disc pressure rises during forward bending in proportion to the sine of the angle of bending forward and to the total weight above the level measured (11). Excessive flexion-extension movement is prevented by the trunk muscles and, ultimately, by the longitudinal ligaments.

Several methods have been employed to measure the range of lumbar movement. In most studies only the flexion movement has been determined, but in others both flexion and extension capacity have been evaluated. The different ways of measuring lumbar movement include the use of fingertips-to-floor gauge, inclinometers, and serial radiographs, as well as various tape-measure methods. The advantage of the tape-measure methods are their simplicity, their low inter- and intraobserver errors, and the absence of discomfort or hazard to the patient (10). As they may explicitly measure only the 
lumbar movement, the results can be supposed to show clear association with other findings on the structure and function of the lumbar spine.

The capacity of maximal lumbar flexion shows a Gaussian distribution in the general population (9). The interindividual variation in the amount of lumbar flexion is large, and mobility of more or less than the mean value of the population need not imply back morbidity.

Restriction of lumbar flexion may be due to ageing, ankylosing spondylitis, acute episodes of painful back disorders, and previous episodes of back disorders.

As age increases, biochemical changes take place in the connective tissues and diminish their elastic properties. A progressive reduction in the capacity to bend forward with advancing age has been demonstrated in several studies. Loebl (6), using an "inclinometer" of his own design, found a mean antero-posterior movement in the lumbar spine of $66^{\circ}$ in males aged 15 to 20 years and $55^{\circ}$ in those between 61 to 70 years. Moll and Wright (9) measured the distance between the lumbosacral junction and a point $10 \mathrm{~cm}$ more cranial in subjects standing straight. In a sample representing the general population they observed a mean increase in distance of $7 \mathrm{~cm}$ during forward bending. An initial increase in mobility from the 15-24 decade to the 25-34 decade was followed by a progressive decrease as age advanced, especially from 65 years on.

Relating the prevalence of restriction and pain among concrete reinforcement workers during forward bending to corresponding findings in other populations requires consideration of both selection and the possible effect of work. On one hand, the high demand reinforcement work puts on the back tissues does not allow unfit persons to start such work or persons developing severe back disease to continue with it. This selection decreases the prevalence of restriction and pain during forward bending in those active in this occupation because working in stooped postures is mandatory for reinforcement workers. It is probable that selection affects the prevalence figures more strongly for reinforcement workers than it does for other occupational groups. On the other hand, the stooped postures in concrete reinforcement work may cause or contribute to restriction and pain during forward bending and thus cause an increase in the prevalence figures.

Analysis of the effect of reinforcement work on restriction and pain during forward bending by the comparison of the occurrence of these variables with the length of reinforcement work experience was found to be difficult because of the strong relation between the worker's age and his time of exposure to the demands of reinforcement work and because most workers had been employed in other physically heavy occupations before entering reinforcement work. It was not possible to show any significant difference in the prevalence of restriction and pain during forward bending between the reinforcement workers of the same age, but with different lengths of experience in reinforcement work.

A comparison of the prevalence of restricted forward bending in reinforcement workers with that of computer technicians (104 Finnish males, aged 20-54 years), investigated by identical methods (12), showed this phenomenon to be almost equally common in both groups. Pain during forward bending was more common among reinforcement workers than among computer technicians (fig. 4). The work of the computer technicians is physically lighter than that of the reinforcement workers, but it involves bent-forward and rotated postures which contribute to the incidence of back symptoms.

Ankylosing spondylitis is a rare disease in persons in heavy physical work - as illustrated by only one case radiologically detected in the 295 concrete reinforcement workers we examined - and thus need not be taken into consideration in epidemiologic studies such as the present one.

Acute back disorders, especially lumbago and sciatica, are often accompanied by temporary restriction of lumbar flexion. Severe low-back pain leads to splinting of the lumbar spine through "spasms" in the paraspinal muscles. Acute, but less intense, back disorders mostly leave the mobility of the lumbar spine unaffected (4).

Residual signs of previous episodes of back pain often persist. Rowe (14) investigated the limitation of forward 
bending in 30- to 49-year-old males without previous back disorders and in others who had already recovered from a back disorder. He classified persons as "stiff" if they were unable to get their fingertips 6 in $(15 \mathrm{~cm})$ or less from the floor. The prevalence of positive findings was $10 \%$ in persons without previous back disorders, $31 \%$ in persons with previous back disorders not necessitating sick leave, and $48 \%$ in persons with a previous back disorder which had necessitated sick leave. Hult (5) also observed restriction of lumbar movement more commonly in persons with a history of back disorders than in persons without. In older age groups the prevalence of restriction was high even among those who had never experienced back disorders. In the concrete reinforcement workers, restricted lumbar flexion was clearly related to a history of previous sciatica but not to a history of lumbago. Pain during bending forward in the clinical examination, probably a more changeable finding than restriction, was also related to previous sciatica but not to lumbago among the reinforcement workers.

The relationship between clinically observed restriction of lumbar flexion and symptoms in the back during an ordinary workday was slight. There was no association with stiffness or with sharp pain, even if both these symptoms might be supposed to be manifestations of lumbar disc degeneration. Some association was found with fatigue and with ache, but this finding does not give any clear clues to the mechanism behind these symptoms.

Diminished trunk muscle strength has been shown to be another "residual" sign of previous back disorder (14). The association between diminished trunk muscle capacity and previous experience of back pain syndromes in reinforcement workers has been presented in another article (13). In the concrete reinforcement workers, both restriction and pain during lumbar flexion were related to impaired performance of both the straight abdominal muscles and the back muscle, but our present data do not enable us to draw conclusions on any possible cause-effect relationship. The increased prevalence of impaired trunk muscle performance in workers with previous back syndromes may be explained as a parallel phenomenon to that of restricted lumbar flexion, both findings being due to a previous back disorder severe enough to leave these residual signs.

Radiological investigation of the lumbar spine is a crude measure of the irreversible morphological changes which take place in the spinal tissues and form the basis for later clinical manifestations of lumbar degeneration, such as restriction of the flexion movement. Thus the correlation between radiologically detectable changes and clinical signs of lumbar degeneration mostly remains low. Disc degeneration as such need not cause restriction of lumbar flexion. The diminution of disc height, observable in radiographs, may temporarily even lead to increased lumbar mobility. However, increased stiffness of the disc tissues and longitudinal ligaments, as well as growth of vertebral osteophytes, will, in time, lead to a diminished range of movement.

In the concrete reinforcement workers the prevalence of radiologically detectable lumbar disc degeneration was considerable in persons without restricted lumbar flexion, but even higher in persons with restriction. This finding is in agreement with those of Hult. Of the reinforcement workers with a moderate or severe restriction of lumbar flexion, almost three men out of four showed radiological signs of lumbar disc degeneration.

\section{REFERENCES}

1. ALLBROOK, D. Movements of the Iumbar spinal column. J. bone jt. surg. 39 B (1957): $2,339-345$.

2. AMERICAN ACADEMY OF ORTHOPAEDIC SURGEONS. Joint motion - Method of measuring and recording. Livingstone, Edinburgh 1966, p. 50.

3. CAILLIET, R. Low back pain syndrome (2nd ed.). F. A. Davis Co., Philadelphia, Pa. 1968. $134 \mathrm{p}$.

4. FINNESON, B. Low back pain. Lippincott, Philadelphia, Pa. 1973, 376 p.

5. HULT, L. Cervical, dorsal and spinal syndromes. Acta orthoped. scand. suppl. 17 (1954) $102 \mathrm{p}$.

6. LOEBL, W. Y. Measurement of spinal posture and range of spinal movement. Ann. phys. med. 9 (1967) 103-110.

7. MANTEL, N. Chi-square tests with one degree of freedom; extensions of the Mantel-Haenszel procedure. J. am. stat. assoc. 58 (1963) 690-700. 
8. MANTEL, N. and BROWN, C. A logistic reanalysis of Ashford and Sowden's data on respiratory symptoms in British coal miners. Biometrics 29 (1973) 649-665.

9. MOLL, J. and WRIGHT, V. Normal range of spinal mobility. Ann. rheum. dis. 30 (1971) 381-386.

10. MOLL, J. and WRIGHT, V. Measurement of spinal movement. In: M. JAYSON (ed.), The lumbar spine and back pain. Sector Publishing Limited, London 1976, pp. 93112.

11. NACHEMSON, A. The effect of forward leaning on lumbar intradiscal pressure. Acta orthop. scand. 35 (1965) 314-328.

12. NUMMI, J., JÄRVINEN, T. and KOSKELA, A. Liikunnan merkitys selkä-ja polvivaivojen ehkäisyssä. (Työolosuhteet no. 9). Institute of Occupational Health, Helsinki 1977. $14 \mathrm{p}$.

13. NUMMI, J., JÄRVINEN, T., STAMBEJ, U. and WICKSTRÓM, G. Diminished dy- namic performance capacity of back and abdominal muscles in concrete reinforcement workers. Scand. j. work environ. \& health 4 (1978); suppl. 1, 39-46.

14. ROWE, L. Low back pain in industry. J. occup. med. 11 (1969): 4, 161-169.

15. SAARI, J. and WICKSTRÖM, G. Load on back in concrete reinforcement work. Scand. j. work environ. \& health 4 (1978): suppl. $1,13-19$.

16. WICKSTROัM, G., HÄNNINEN, K., LEHTINEN, M. and RIIHIMAKI, H. Previous back syndromes and present back symptoms in concrete reinforcement workers. Scand. j. work environ. \& health 4 (1978): suppl. 1, 20-28.

17. WIIKERI, M., NUMMI, J., RIIHIMÄKI, H. and WICKSTRÖM, G. Radiologically detectable lumbar disc degeneration in concrete reinforcement workers. Scand. $j$. work environ. \& health 4 (1978): suppl. 1, $47-53$. 